Mo-bound methyl group. (ii) The coupling constant between the methyl protons and the ${ }^{31} \mathrm{P}$ nuclei increases from $1.8 \mathrm{~Hz}$ at -20 ${ }^{\circ} \mathrm{C}$ (at lower temperatures the corresponding signal is unresolved) to $3.0 \mathrm{~Hz}$ at $20^{\circ} \mathrm{C}$. For comparison, in the structurally characterized methyl-tungsten complexes ${ }^{5 b, c} \mathrm{~W}\left(\mathrm{CH}_{3}\right)(\mathrm{L}-\mathrm{L})(\mathrm{CO})_{2}$ $\left(\mathrm{PMe}_{3}\right)_{2}\left(\mathrm{~L}-\mathrm{L}=\mathrm{acac}, \mathrm{S}_{2} \mathrm{CNR}_{2}, \mathrm{~S}_{2} \mathrm{COR}\right)$ this coupling ranges from 3.5 to $8 \mathrm{~Hz}$. (iii) The solution IR spectrum of $4\left(20^{\circ} \mathrm{C}\right)$ is more complex than those of 1-3 and shows, in addition to bands due to the carbonyl functionalities in the agostic and $\eta^{2}$-acyl isomers, two absorptions at ca. 1912 and $1836 \mathrm{~cm}^{-1}$ which can be tentatively assigned to the terminal carbonyl ligands in the methyl dicarbonyl species $\mathrm{Mo}\left(\mathrm{CH}_{3}\right)\left(\mathrm{S}_{2} \mathrm{CO}-i\right.$ - $\left.\mathrm{Pr}\right)\left(\mathrm{CO}_{2}\right)\left(\mathrm{PMe}_{3}\right)_{2}$.

In conclusion, our results indicate that in the system under investigation there are small energy differences among the isomeric structures A, B, and C, so that both types of acyl coordination, B and C, are kinetically and thermodynamically accessible from their isomeric alkyl-carbonyl structure A. Since most of the acyl complexes of molybdenum known to date have $\eta^{2}$ structures while the only known agostic acyls are those discussed in this paper, it seems that the $\mathrm{C}-\mathrm{H}$...Mo interaction becomes structurally and thermodynamically competitive only in the presence of strongly electron releasing ligands such as the dithiocarbamates and xanthates. Note however that the analogous tungsten complexes have alkyl-carbonyl structures. ${ }^{5}$ Therefore it is clear that very subtle electronic effects must be responsible for the observation in the present system of the three isomeric structures A, B, and C.

Registry No. 2, 133400-33-6; 3, 133400-32-5; 4, 133400-34-7; 5A, 133400-29-0; 5B, 133400-30-3; 5C, 133400-31-4; $\mathrm{Mo}\left(\eta^{2}-\mathrm{C}(\mathrm{O}) \mathrm{CH}_{3}\right) \mathrm{Cl}-$ (CO) $\left(\mathrm{PMe}_{3}\right)_{3}, 89727-04-8 ; \mathrm{NaS}_{2} \mathrm{CN}-i$ - $\mathrm{Pr}_{2}, 4092-82-4 ; \mathrm{NaS}_{2} \mathrm{CNC}_{5} \mathrm{H}_{10}$. 873-57-4; $\mathrm{NaS}_{2} \mathrm{COMe}, 6370-03-2 ; \mathrm{NaS}_{2} \mathrm{CO}-i-\mathrm{Pr}, 140-93-2$.

\section{On the Transition States of Electrophilic Radical Additions to Alkenes}

Hendrik Zipse, ${ }^{\dagger}$ Jianing He, ${ }^{\dagger}$ K. N. Houk, ${ }^{\dagger}$ and Bernd Giese*,†

\section{Institute of Organic Chemistry, University of Basel St. Johanns-Ring 19, CH-4056 Basel, Switzerland Department of Chemistry and Biochemistry University of California-Los Angeles Los Angeles, California 90024 \\ Received December 12, 1990}

Revised Manuscript Received March 30, 1991

Carbon-centered radicals are nucleophilic or electrophilic species, depending upon the substituent at the radical center. Electron-donating substituents like alkyl or alkoxy groups increase the nucleophilicity ${ }^{1}$ of radicals whereas electron-withdrawing substituents like ester or nitrile groups augment their electrophilic ${ }^{2}$ behavior. Calculations for a variety of cases have shown that nucleophilic radicals approach the olefinic carbon atoms at angles between $104^{\circ}$ and $108^{\circ}$ at the UHF/3-21G level. ${ }^{3}$ Figure 1 shows the geometry for the addition of the methyl radical to ethylene at the UHF/6-31G* level. ${ }^{3 \mathrm{~b}}$

\footnotetext{
- Author to whom correspondence should be addressed.

'University of Basel.

'University of California.

(1) (a) Citterio, A.; Minisci, F.; Porta, O.; Sesana, G. J. Am. Chem. Soc. 1977, 99, 7960. (b) Giese, B. Angew. Chem. 1983, 95, 771; Angew. Chem.
} Int. Ed. Engl. 1983, 22, 753.

(2) (a) Riemenschneider, K.; Bartels, H. M.; Dornow, R.; Drechsel-Grau, E.; Eichel, W.; Luthe, H.; Matter, Y. M.; Michaelis, W.; Boldt, P. J. Org. Chem. 1987, 52, 205. (b) Gleicher, G. J.; Mahiou, B.; Aretakis, A. J. J. Org. Chem. 1989, 54, 308. (c) Giese, B.; He, J.; Mehl, W. Chem. Ber. 1988, 121 , 2063.

(3) (a) Houk, K. N.; Paddon-Row, M. N.; Spellmeyer, D. C.; Rondan, N. G.: Nagase, S. J. Org. Chem. 1986, 51, 2874. (b) Gonzalez, C.; Sosa, C. Schlegel, H. B. J. Phys. Chem. 1989, 93, 2435. (c) Sosa, C.; Schlegel, H. B J. Am. Chem. Soc. 1987, 109, 4193.

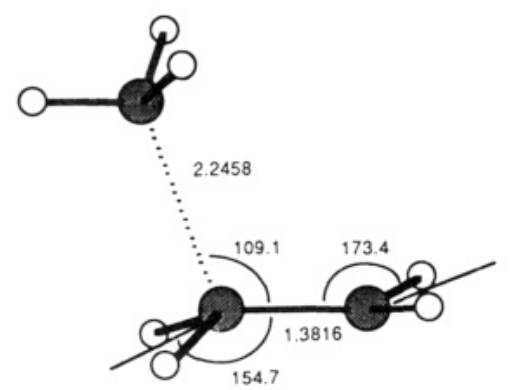

Figure 1. UHF $/ 6-31 G^{*}$ transition state for the addition of the methyl radical to ethylene.

Scheme I

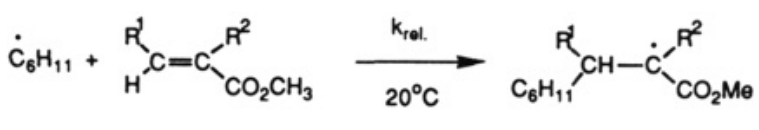

23

Scheme II

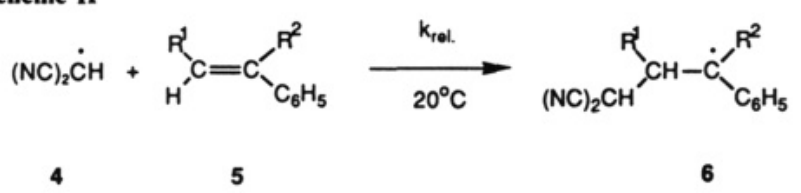

Scheme III

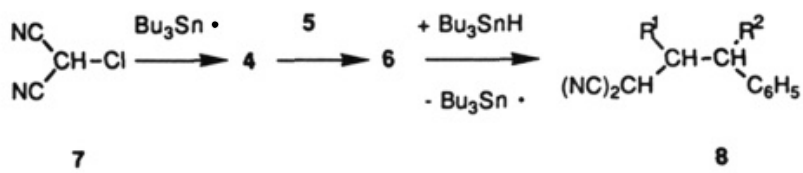

Table I. Values of $k_{\text {rel }}$ for Reaction Depicted in Scheme II

\begin{tabular}{llrllr}
\hline $\mathrm{R}^{1}$ & \multicolumn{1}{c}{$\mathrm{R}^{2}$} & \multicolumn{1}{c}{$k_{\text {rel }}$} & \multicolumn{1}{c}{$\mathrm{R}^{1}$} & $\mathrm{R}^{2}$ & \multicolumn{1}{c}{$k_{\text {rel }}$} \\
\hline $\mathrm{H}$ & $\mathrm{H}$ & $\equiv 1000$ & $\mathrm{H}$ & $\mathrm{H}$ & $\equiv 1000$ \\
$\mathrm{H}$ & $\mathrm{CH}_{3}$ & 820 & $\mathrm{CH}_{3}$ & $\mathrm{H}$ & 110 \\
$\mathrm{H}$ & $\mathrm{C}_{2} \mathrm{H}_{5}$ & 360 & $\mathrm{C}_{2} \mathrm{H}_{5}$ & $\mathrm{H}$ & 20 \\
$\mathrm{H}$ & $i-\mathrm{C}_{3} \mathrm{H}_{7}$ & 120 & $i-\mathrm{C}_{3} \mathrm{H}_{7}$ & $\mathrm{H}$ & $<1$ \\
\hline
\end{tabular}

Transition state $\mathbf{1}$ is also in accord with substituent effects on rates. Thus, in addition of the nucleophilic cyclohexyl radical 2 to substituted acrylates 3 (Scheme I), alkyl groups $R^{2}$ reduce the rate of addition only slightly, but alkyl groups $R^{1}$ at the attacked olefinic carbon atom exert huge rate-decreasing effects. ${ }^{16}$ Absolute rate measurements for reactions of tert-butyl radicals with various alkenes exhibit comparable results. ${ }^{4}$

These unequal substituent effects point to unsymmetrical transition states 1 in which only the attacked olefinic carbon atom deviates considerably from its ground-state geometry. Therefore substituents at this center exhibit large steric effects. Normally nucleophiles and electrophiles add to carbonyls and alkenes with quite different geometries. ${ }^{5}$ It was therefore of interest to determine to what extent electrophilic and nucleophilic radicals differ in their transition-state geometries.

We have now shown that addition reactions of electrophilic malononitrile radical 4 with substituted styrenes 5 (Scheme II, Table I) give similar results to nucleophilic radicals, providing the first experimental evidence for the transition-state geometry of electrophilic radical addition. ${ }^{5}$

Substituents $\mathbf{R}^{1}$ at the attacked carbon atom of alkenes $\mathbf{5}$ exert much larger rate-decreasing effects than adjacent substituents $R^{26}{ }^{6}$

(4) (a) Münger, K.; Fischer, H. Int. J. Chem. Kinet. 1985, 17, 809. (b) Fischer, H. In Free Radicals in Synthesis and Biology; Viehe, H. G., Janousek, Z., Merenyi, R., Eds.; Reidel: Dordrecht, 1986; p 123.

(5) Houk, K. N.; Paddon-Row, M. N.; Rondan, N. G.; Wu, Y.-D.; Brown, F. K.; Spellmeyer, D. C.; Metz, J. T.; Li, Y.; Loncharich, R. J. Science 1986, 231,1108 . 


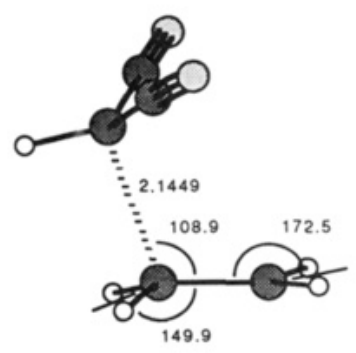

9 a

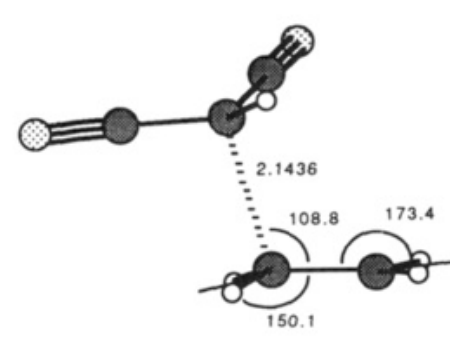

$9 \mathrm{~b}$
Figure 2. Transition states for the addition of the malononitrile radical to ethylene at the UHF/6-31G* level.

The electrophilic radical $\mathbf{4}$ was generated via chlorine abstraction from chloromalononitrile 7 with tributylstannane at $20^{\circ} \mathrm{C}$ in tetrahydrofuran under irradiation (Scheme III). The malononitrile radicals are trapped by styrene $\mathbf{5}$ and give adduct radicals 6 that yield products 8 after hydrogen abstraction from tributylstannane. In kinetic competition reactions, a 10 -fold or greater excess of pairs of styrenes was used. Determination of the product ratio via gas chromatography gives relative rates via pseudo-first-order kinetics. $2 \mathrm{c}, 7$

Under the conditions of these kinetic experiments, trapping of radical 6 by tributyltin hydride $(6 \rightarrow 8)$ is faster than $\beta$-bond cleavage to starting alkene 5 and educt radical $4(6 \rightarrow 4+5) .^{8}$ This was shown in reactions with $\beta$-methylstyrene where no isomerization of the cis styrene to the more stable trans compound could be observed.

Thus the results of kinetic experiments favor an unsymmetrical transition state for the addition reaction of electrophilic radicals to alkenes. To provide theoretical evidence for this conclusion, $\mathrm{ab}$ initio calculations were carried out for the transition state of the addition of the malononitrile radical 4 to ethylene. ${ }^{9}$ The two transition states $\mathbf{9 a}$ and $\mathbf{9 b}$ are shown in Figure 2. Transition-state structures with angles of attack smaller than $90^{\circ}$ could not be found.

The energy difference between reactants and the transition states $9 \mathrm{a}$ and $9 \mathrm{~b}$ are $14.5 \mathrm{kcal} / \mathrm{mol}$ and $14.3 \mathrm{kcal} / \mathrm{mol}$ at the UHF/6-31G*//UHF/6-31G* level. ${ }^{10}$ Inclusion of electron correlation effects lowers the energy difference considerably to $8.8 \mathrm{kcal} / \mathrm{mol}$ for $9 \mathrm{a}$ and $8.6 \mathrm{kcal} / \mathrm{mol}$ for $9 \mathrm{~b}$ at the PMP3/6$31 \mathrm{G}^{*} / / \mathrm{UHF} / 6-31 \mathrm{G}^{*}$ level of theory. From Figure 2 it can be seen that the geometries for the two transition states are very similar. A comparison with the transition state 1 shows that the differences in geometry between approach of the electrophilic malononitrile radical $\mathbf{4}$ and the nucleophilic methyl radical to ethylene are rather small. Only the distance between the reactants is slightly shorter for the malononitrile radical $(2.14 \AA)$ as compared to the methyl radical $(2.25 \AA)$. The pyramidalization of

(6) A referee questioned why $\alpha$-methylstyrene is less reactive with malononitrile radicals than styrene. The electrophilic trichloromethyl radical reacts 4.2 times faster with $\alpha$-methylstyrene than styrene at $80^{\circ} \mathrm{C}$ (Kharasch, M. S.; Simon, E.; Nudenberg, W. J. Org. Chem. 1953, 18, 328). It is possible that the transition state for the malononitrile radical addition is located later on the reaction coordinate, so that steric effects are slightly larger.

(7) The kinetic method is described in the following: Giese, B.; Meixner, J. Chem. Ber. 1981, //4, 2138 .

(8) In cyclization reactions, reversibility in additions of electrophilic radicals was observed in the absence of effective radical traps: Julia, M. Pure Appl. Chem. 1987, 40, 553.

(9) Calculations were carried out by using GAUSSIAN 90. For geometry optimizations and frequency calculations, the $6-31 G^{*}$ basis set was used with UHF wave functions. Zero point energies were scaled by 0.9 . Post-SCF energies were determined by PMP3/6-31G* calculations with projection of the first spin contaminant as implemented by H. B. Schlegel (J. Chem. Phys. 1986, 84, 4530).

(10) Absolute energies calculated at various computational levels for transition state 9a: UHF/6-31G*//UHF/6-31G*, -301.0464804; PMP3/ $6-31 \mathrm{G}^{*} / / \mathrm{UHF} / 6-31 \mathrm{G}^{*},-301.9897336$. For $9 \mathrm{~b}$ : UHF $/ 6-31 \mathrm{G}^{*} / / \mathrm{UHF} / 6$ $31 \mathrm{G}^{*},-301.0467342 ; \mathrm{PMP} 3 / 6-31 \mathrm{G}^{*} / / \mathrm{UHF} / 6-31 \mathrm{G}^{*},-301.9899853$. For the malononitrile radical: UHF/6.31G*//UHF/6-31G*, -223.037874; PMP3/6-31G*//UHF/6-31G*, -223.6983886. For ethylene: HF/6$31 \mathrm{G}^{*} / \mathrm{HF} / 6-31 \mathrm{G}^{*},-78.0317181$; $\mathrm{MP3} / 6-31 \mathrm{G}^{*} / / \mathrm{HF} / 6-31 \mathrm{G}^{*}$, -78.3053641 . Zero point energies (in $\mathrm{kcal} / \mathrm{mol}$ and scaled by 0.9 ): $9 \mathrm{a}, 50.3$; 9b, 50.53; malononitrile radical, 17.9; ethylene, 30.9 . the ethylene carbon atom being attacked is $155^{\circ}$ for the methyl radical and $150^{\circ}$ for the malononitrile radical. These parameters could indicate a somewhat later transition state for the reaction of malononitrile radical 4 with ethylene (transition states 9) compared to that of addition of methyl radicals (transition state 1). However, the angle of attack is virtually identical for both systems.

The addition of the electrophilic, heteroatom-based hydroxyl radical to ethylene had been investigated earlier. ${ }^{3}$ In this transition state the radical approaches the ethylene terminus by an angle of $106.4^{\circ}$. Comparison of the transition structures of nucleophilic radicals ${ }^{3,11}$ to ambiphilic radicals $\left({ }^{\circ} \mathrm{CH}_{2} \mathrm{CHO}\right)^{11}$ provides additional computational support for the near constancy of the attack angle $\alpha$ regardless of the nature of the radical.

Acknowledgment. We are grateful to the Swiss National Fonds and the National Science Foundation for financial support and the UCLA Office of Academic Computing for IBM 3090/600J computer time.

Supplementary Material Available: Geometrical data for the transition states $9 \mathbf{a}$ and $\mathbf{9 b}$ ( 2 pages). Ordering information is given on any current masthead page.

(11) Zipse, H.; Giese, B.; Broeker, J.; Li, Y.; Houk, K. N., unpublished results.

\section{Dependence of Electron Transfer Rates on Donor-Acceptor Angle in Bis-Porphyrin Adducts}

Anna Helms, David Heiler, and George McLendon*

Department of Chemistry, University of Rochester Rochester, New York 14627

Received March 1, 1991

Revised Manuscript Received March 29, 1991

Electron transfer reactions between spatially fixed donor-acceptor pairs play a key role in processes ranging from biology to xerography. ${ }^{1}$ When the donor-acceptor separation is much larger than van der Waals contact distance, the electron transfer rate constant, $k_{\mathrm{et}}$, depends markedly on wave function mixing which is characterized by a tunneling matrix element, $\left.|\mathrm{Vab}|\right|^{1,2} k_{\mathrm{et}} \propto$ $|\mathrm{Vab}|^{2}$. A wide variety of experiments have probed the dependence of rate on donor-acceptor distance, showing that $|\mathrm{Vab}| \alpha \exp (-$ $\beta R) .^{1 \mathrm{~b}}$ Since the interacting wave functions contain not only a radial component but also an angular one, electron transfer rates might also depend markedly on the angle between the donor and acceptor. This question is of some importance in understanding biological electron transfer and has received significant theoretical attention. $^{3}$ There is some experimental indication of such angular effects on rate in recent studies by Closs and Miller ${ }^{4}$ of bichromophoric molecules. ${ }^{4}$ However, unlike the well-established dependence of rate on distance, no systematic experimental studies of the dependence of rate on donor-acceptor angle are available, although recent studies ${ }^{5}$ by Sessler, Morayuma, and others may bear on this problem. We now report the first such systematic study, using bis-porphyrin compounds of the general structure in

(1) (a) Marcus, R.; Sutin, N. Biochim. Biophys. Acta 1985, 811, 265-312. (b) A general review of recent work can be found in the following monograph: Electron Transfer in Organic, Inorganic, and Biological Systems; Advances in Chemistry 228; American Chemical Society: Washington, DC, 1991.

(2) Miller, J. R.; Beitz, J. J. Chem. Phys. 1981, 74, 6746-6753.

(3) (a) Cave, R.; Marcus, R.; Siders, P. J. Phys. Chem. 1986, 90, 1436-1444. (b) Ohta, K.; Closs, G.; Morokuma, K.; Green, N. J. Am. Chem. Soc. 1986, 108, 1319-1326.

(4) Closs, G.; Calcaterra, L.; Green, N.; Penfield, K.; Miller, J. R. J. Phys. Chem. 1986, 90, 3073.

(5) (a) Osuka, A.; Maruyama, N.; Mataga, N.; Asaki, T.; Yamazaki, I.; Tamdi, H. J. Am. Chem. Soc. 1990, 112, 4958. (b) Sessler, J.; Johnson, M.; Lin, T. Y.; Creager, S. J. Am. Chem. Soc. 1988, 110, 3659. 